\title{
pH-Activated Size Reduction of Large Compound Nanoparticles for in vivo Nucleus-Targeted Drug Delivery
}

\author{
Yanbin Fan, ${ }^{\mathrm{a}}$ Chunyan $\mathrm{Li}^{\mathrm{b}}{ }^{\mathrm{b}}$ Fuyou $\mathrm{Li}^{* \mathrm{~b}}$ and Daoyong Chen ${ }^{*^{\mathrm{a}}}$
}

\begin{abstract}
a. The State Key Laboratory of Molecular Engineering of Polymers, Department of Macromolecular Science, Fudan University, Shanghai, 200433, P. R. China. E-mail: chendy @ fudan.edu.cn.

b. Department of Chemistry \& Institute of Biomedicine Science \& Collaborative Innovation Center of Chemistry for Energy Materials, Fudan University, Shanghai, 200433, P. R. China. E-mail: fyli@fudan.edu.cn.
\end{abstract}

\begin{abstract}
Nucleus-targeted drug delivery is a promising strategy for anticancer therapy, but in vivo nucleus-targeted drug delivery has been challenging. Limited by the channel size of the nucleopore, vehicles that enter the nucleus via the nucleopore actively should be small and decorated with nuclear localization signal (NLS). However, the small vehicle size may promote leakage of vehicles into normal tissues, and the positively-charged NLS can lead to strong non-specific interactions in vivo. In the present study, we demonstrate an in vivo nucleus-targeted drug delivery using large compound nanoparticles with detachable PEG shell. The nanoparticles are composed of PEG-benzoic imine-oligo- $L$-lysine/iridium(III) metallodrug complex and formed in a kinetically-controlled fashion. Under physiological conditions $(\mathrm{pH}$ 7.4), the nanoparticles are large (ca. $150 \mathrm{~nm}$ ) and protected by an inert PEG shell. When internalized into intracellular acidic endo/lysosomes of cancer cells, the nanoparticles dissociate into smaller ones ( $\mathrm{ca} .40$ $\mathrm{nm}$ ) and the PEG chains detach due to the cleavage of the benzoic imine bond at low $\mathrm{pH}$. The small nanoparticles, with exposure of the oligo- $L$-lysine after the detachment of the PEG shield, then translocate into the nucleus via the nucleopore due to the small size and nuclear localization ability of the oligo- $L$-lysine. Importantly, the small particles could significantly release the contained drug into the nucleus, leading to $c a$. 20-fold higher cytotoxicity compared to the native drug in vitro. Further in vivo application of the nucleus-targeting nano-system in a nude-mice model showed significant tumor inhibition and remarkable life-span elongation.
\end{abstract}

Key Words iridium (III), nanomedicine, cancer therapy, nucleus-targeting

\section{Introduction}

Nanocarriers incorporating anticancer agents can potentially mitigate the side effects of conventional chemotherapy by selectively delivering these agents to regions of disease [1] and minimizing the dosage required for efficacy [2]. Typically, the vehicles release molecules into the cytosol [3], and not into the nucleus, where most anticancer drugs exert their effects [4]. Although the drugs released into the cytosol can enter the nucleus by simple diffusion [5], cancer cells, especially drug-resistant cancer cells, can evolve various intracellular drug-resistance mechanisms to limit the nuclear entry of cytosolic drugs [4-7]. Consequently, only a small percentage of drugs 
delivered into the cytosol finally reach the nucleus [4,8]. Thus, designing and preparing drug-containing nanocarriers that are capable of translocating into the nucleus of cancer cells and then releasing the drug inside the nucleus could dramatically improve the efficacy of therapy $[3,4,7,9,10]$.

Usually, cargoes enter the nucleus either when the cell undergoes mitosis (during mitosis, the nuclear membrane, the only barrier between the cytosol and nucleus, temporarily disassembles) or via the nucleopore [3]. Nuclear entry of cargoes via the nucleopore pathway is more efficient as the cargoes can take advantage of both the mitosis and nucleopore pathways for nuclear entry. Limited by the channel size of the nucleopore, cargoes larger than the channel size are prevented from crossing the nuclear envelope via the nucleopore [11], while those smaller than the channel size but larger than $10 \mathrm{~nm}$ can go through the nucleopore only when they bear a nuclear localization signal (NLS) on the surface [7,9,10]. Although cargoes smaller than $10 \mathrm{~nm}$ can diffuse freely through the nucleopore without a NLS, the nuclear entry will be greatly promoted in the presence of a NLS [10,11]. Therefore, cargoes capable of going through the nucleopore efficiently should be small (less than $50 \mathrm{~nm}$ [9a,12]) and have a NLS on the surface. For example, it has been reported that the conjugates of anticancer drugs and a NLS using intranuclear-cleavable conjugation bonds can go through the nucleopore efficiently and reach the nucleus of cancer cells, and then release the drug there [7]. However, almost all of the drug conjugates that have been reported to enter the nucleus are small ( $c a$. few nanometers), resulting in susceptibility to excretion by the kidneys [13] and unintentional leakage into other sites (e.g. capillaries and normal tissues) [14]. Furthermore, cleavage of the conjugation bonds in the lysosome rather than in the nucleus further decreases the efficiency of nuclear delivery.

Design of nanosystems for in vivo nucleus-targeted drug delivery has been challenging due to incompatible physiochemical requirements on the nanosystems going through in sequence of blood, extracellular matrix, and cytoplasm to ultimately the intracellular nucleus [3]. Recently, NLS-decorated nanoparticles have been explored as nanosystems for in vivo nucleus-targeted drug/gene delivery. These systems include charge-reversible magnetic mesoporous silica nanoparticles with TAT peptide [12], membrane-core nanoparticles with arginine-rich peptide [15], and mesoporous silica nanoparticles with TAT and RGD peptides [16,17]. However, most of the nanoparticles are small in diameter (less than $50 \mathrm{~nm}$ ) which may promote unintentional leakage from vasculature into normal tissues and cause systematic toxicity [14]. Besides, the NLS is usually positively charged and thus could elicit strong non-specific interactions in vivo $[3,18]$. In the present study, to meet with the requirements of nanoparticles for in vivo applications and nuclear entry via the nucleopore, we designed and prepared kinetically-controlled large compound 
nanoparticles with detachable PEG shell and folate decoration (denoted as LNP dePEG-FA). $_{\text {) }}$ LNP $_{\text {dePEG-FA }}$ results from self-assembly of PEG-benzoic imine-oligo- $L$-lysine/iridium(III) metallodrug complex and further folate-functionalization of the nanoparticles. LNP $_{\text {dePEG-FA }}$ has a large size of $c a .150 \mathrm{~nm}$ and bears an inert PEG shell under neutral conditions. Interestingly, after internalization into the acidic endo/lysosomes of cancer cells, LNP $_{\text {dePEG-FA }}$ dissociates into smaller nanoparticles (SNPs, ca. $40 \mathrm{~nm}$ ) and meanwhile the PEG chains are detached due to breakage of the benzoic imine bond. The detachment of PEG chains makes the previously shielded NLS oligo- $L$-lysine exposed then. So SNPs with oligo- $L$-lysine on their surfaces can enter the nucleus via the nucleopore due to the small size and the nuclear localization ability of oligo-L-lysine. LNP $_{\text {dePEG-FA }}$ leads to $c a$. 20-fold higher toxicity in vitro, greater tumor suppression in mice and a much longer life-span of the mice compared to the native drug, indicating the ability of the nucleus-targeting LNP $_{\text {dePEG-FA }}$ for cancer therapy.

(A)

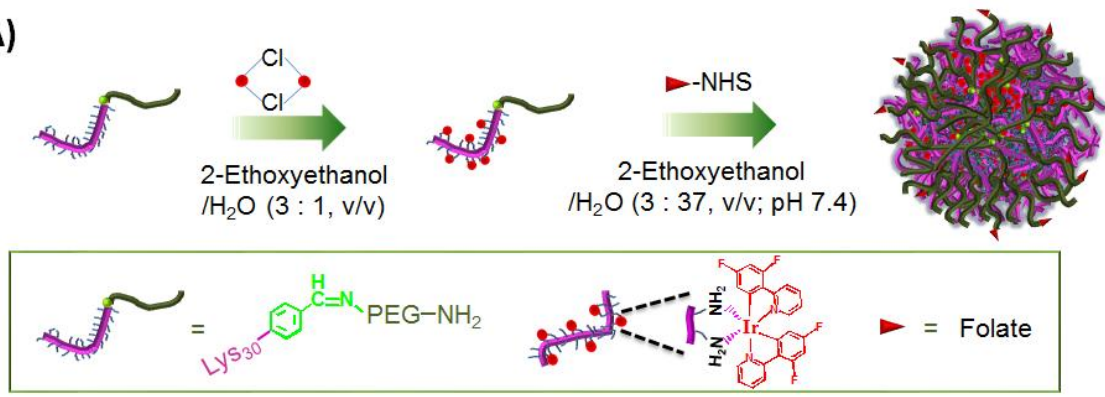

(B)

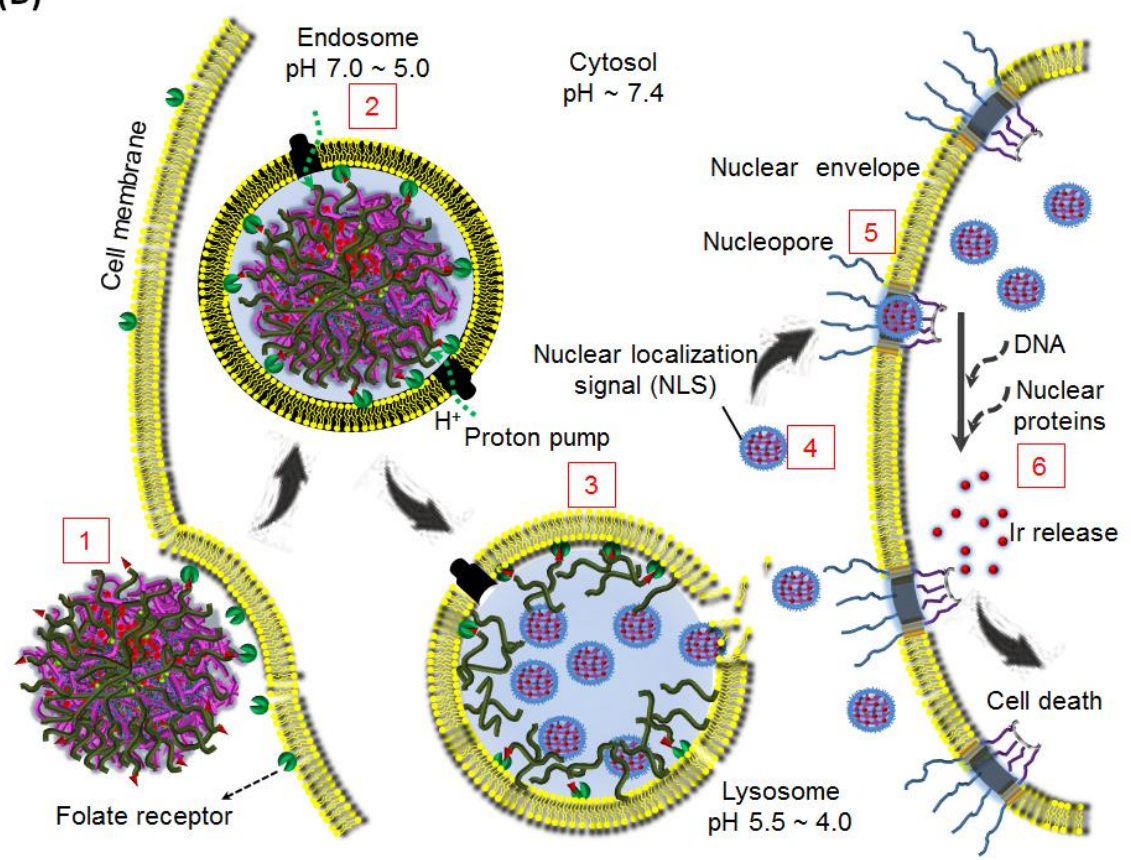

Scheme 1 (A) Schematic illustration of the preparation of the kinetically-controlled large compound nanoparticles (LNP dePEG-FA ). (B) The dynamic behavior of $\mathrm{LNP}_{\text {dePEG-FA }}$ passing through multiple barriers from vascular environment to the nucleus. (1) $\mathrm{LNP}_{\text {dePEG-FA }}$ binds to tumor cells due to the folate-folate receptor affinity, (2) becomes internalized by receptor-mediated endocytosis, (3) dissociates into smaller nanoparticles (SNPs) and detaches from PEG chains upon endo/lysosome acidification. 
(4) The small nanoparticle SNP escapes into the cytosol, (5) translocates into the nucleus via the nucleopore with oligo- $L$-lysine acting as a NLS, and (6) releases Ir(III) metallodrug in the nucleus by DNA/SNP interaction and induces cell death.

\section{Results and discussion}

\section{Design and synthesis of PEG- $b$-oligo-L-lysine/iridium(III) amphiphilic complexes}

A potential anti-cancer drug iridium (III) complex was chosen in this study due to its high hydrophobicity that drives self-assembly of its amphiphilic complexes with the double-hydrophilic block copolymer in water, affinity to His residues of proteins [19], significant cytotoxicity [20] and good fluorescence property for ease of tracking [24]. Due to hydrophobicity of the native drug, we designed and synthesized an amphiphilic complex of the metallodrug iridium(III) with PEG- $b$-oligo- $L$-lysine double-hydrophilic block copolymer to enhance drug solubility and form a nucleus-targeting drug delivery system. The PEG- $b$-oligo- $L$-lysine copolymer $\left(\mathrm{Lys}_{30}-\mathrm{CH}=\mathrm{N}-\mathrm{PEG}-\mathrm{NH}_{2}\right.$ ) contains four functional moieties, terminal amine groups for conjugation with a cell penetrating moiety FA [21], oligo-L-lysine Lys 30 as a NLS [22], pH responsive [23] and the metallodrug reactive moiety [24], PEG to protect against non-specific interactions in vivo, and benzoic imine bonds as pH-cleavable linkers [25] between PEG and oligo-L-lysine blocks (Scheme 1a).

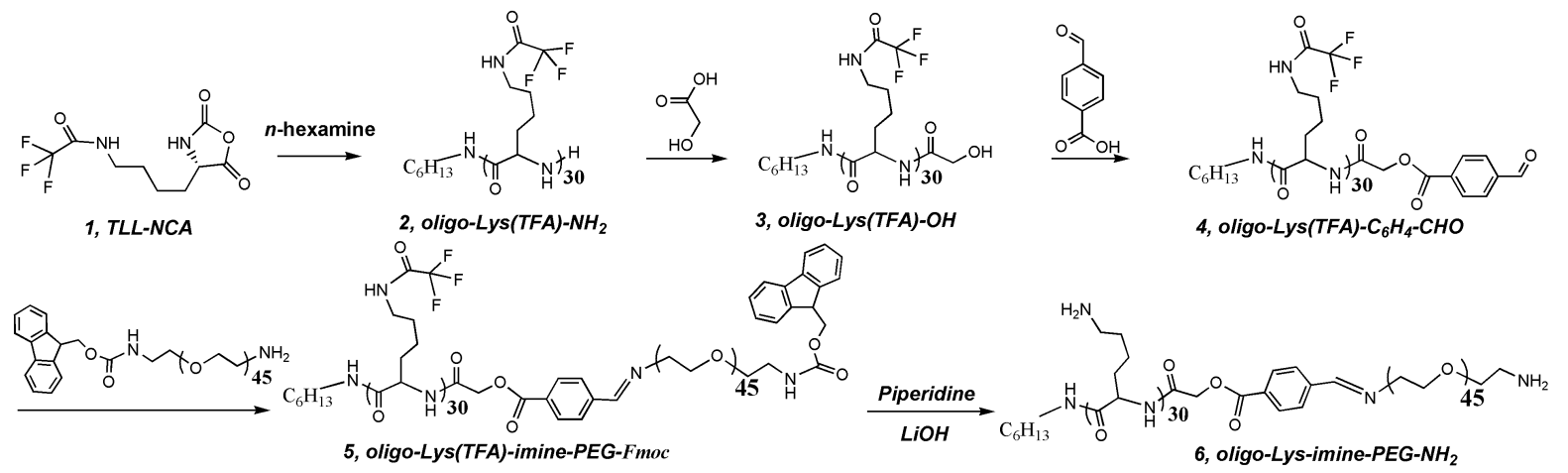

Scheme 2 Synthetic route of the detachable, amine-terminated, PEGlyated block copolymer $\mathrm{Lys}_{30}-\mathrm{CH}=\mathrm{N}-\mathrm{PEG}-\mathrm{NH}{ }_{2}$.

The synthetic routine of the detachable, amine-terminated, PEGlyated block copolymer $\mathrm{Lys}_{30}-\mathrm{CH}=\mathrm{N}-\mathrm{PEG}-\mathrm{NH}_{2}(6)$ was shown in Scheme 2 (the details of all the synthesis are described in the supporting information (SI)). For synthesis of the block copolymer, amine-terminated oligo(trifluoroacetyl- $L$-lysine), $\operatorname{Lys}(T F A)_{30}-\mathrm{NH}_{2}(2$, Scheme 2), with a degree of polymerization of 30 was firstly synthesized via ring-opening polymerization of trifluoroacetyl- $L$-lysine- $N$-carboxy-anhydride (1) using $n$-hexamine as the initiator (confirmed by ${ }^{1} \mathrm{H}$ NMR analysis; Fig. SNMR-1 in SI). The terminal amine of $\operatorname{Lys}(T F A)_{30}-\mathrm{NH}_{2}(2)$ was then converted into a hydroxyl group based on the amide formation between glycolic acid $\left(\mathrm{OH}-\mathrm{CH}_{2}-\mathrm{CO}_{2} \mathrm{H}\right)$ and $\mathrm{Lys}(T F A)_{30}-\mathrm{NH}_{2}$ to give a hydroxyl-terminated $\mathrm{Lys}(T F A)_{30}-\mathrm{OH}(3$, Scheme 
2); ca. $92 \%$ of conversion; Fig. SNMR-2 in SI). Then, Lys(TFA) $)_{30}-\mathrm{OH}(3)$ e was reacted with 4-carboxybenzaldehyd to convert $\operatorname{Lys}(T F A)_{30}-\mathrm{CHO}$ (4, Scheme 2) with a terminal aldehyde group, based on the esterification reaction between the carboxylic group of carboxybenzaldehyde and hydroxyl group of Lys(TFA) $)_{30} \mathrm{OH}$ (3) (ca. 74\% of conversion; Fig. SNMR-3 in SI). The final block copolymer $\mathrm{Lys}_{30}-\mathrm{CH}=\mathrm{N}-\mathrm{PEG}-\mathrm{NH}_{2}(\mathbf{6})$ was then obtained after the imine bond formation between the benzoic aldehyde group of $\operatorname{Lys}(T F A)_{30}-\mathrm{CHO}$ (4) and the $\mathrm{NH}_{2}$ group of 9-fluorenylmethoxycarbonyl mono-protected diamine polyethylene glycol ( $f m o c-\mathrm{HN}-\mathrm{PEG}-\mathrm{NH}_{2}$ ), followed by de-protection of the fmoc and trifluoroacetyl groups and dialysis to remove unreacted PEG and Lys $_{30}$ (Scheme 2). ${ }^{1} \mathrm{H}$ NMR spectroscopy and gel permeation chromatography (GPC) were used to characterize the polymers and the results confirmed significant formation of the benzoic imine bond and the resultant PEG/oligo-L-lysine block copolymer, respectively (Fig. SNMR-4 and Fig. S1A in SI).

Lys $_{30}-\mathrm{CH}=\mathrm{N}-\mathrm{PEG}-\mathrm{NH}_{2} /$ iridium(III) complex was then synthesized via a $12-\mathrm{h}$ reaction of the intermediate $\left[\operatorname{Ir}(\mathrm{dfppy})_{2} \mu-\mathrm{Cl}\right]_{2}(\mathrm{dfppy}=2$,4-difluorophenyl-2-pyridine) and the block copolymer $\mathrm{Lys}_{30}-\mathrm{CH}=\mathrm{N}-\mathrm{PEG}-\mathrm{NH}_{2}$ in a mixture solvent of 2-ethoxyethanol/ $\mathrm{H}_{2} \mathrm{O}(3: 1, v / v)$ at $110{ }^{\circ} \mathrm{C}$ under argon atmosphere (Scheme S7 in SI) [24]. In the complex, the highly hydrophobic Ir(III) moieties were grafted to part of the $\operatorname{Lys}_{30}$ block via N-Ir coordination bond formation (Scheme 1), thus imparting an amphiphilic nature to the complex.

\section{Preparation and characterization of the kinetically controlled large compound nanoparticles}

Kinetically controlled large compound nanoparticles were subsequently prepared by diluting the $\mathrm{Lys}_{30}-\mathrm{CH}=\mathrm{N}-\mathrm{PEG}-\mathrm{NH}_{2} / \mathrm{Ir}$ (III) complex in the mixture solvent with neutral water ( $\mathrm{pH} 7.4$ ) to cause abrupt assembly of the complex. Large compound nanoparticles with a detachable PEG shell and folate decoration $\left(\mathrm{LNP}_{\text {dePEG-FA }}\right)$ were then obtained after reaction of the nanoparticles with $\mathrm{N}$-hydroxysuccinimide ester of folate (FA-NHS) and dialysis of the particle suspension against water at $\mathrm{pH} 7.4$ (Scheme 1A). As determined by ICP-MS, the payload and encapsulation efficiency of $\operatorname{Ir}(\mathrm{dfppy})_{2}{ }^{+}$in $\mathrm{LNP}_{\text {dePEG-FA }}$ were found to be $10.6 \%(\mathrm{w} / \mathrm{w})$ and $61.0 \%$, respectively. 
(A)

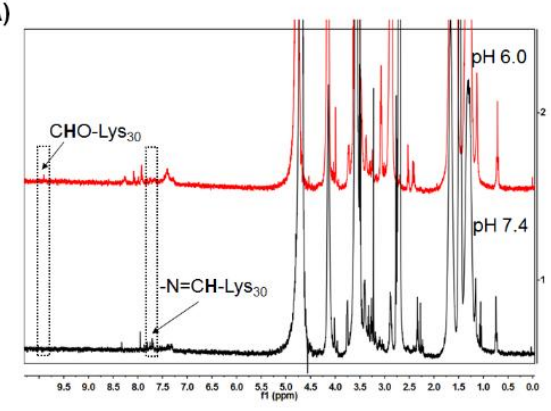

(C)

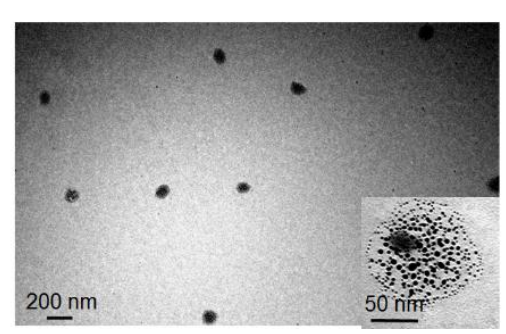

(B)

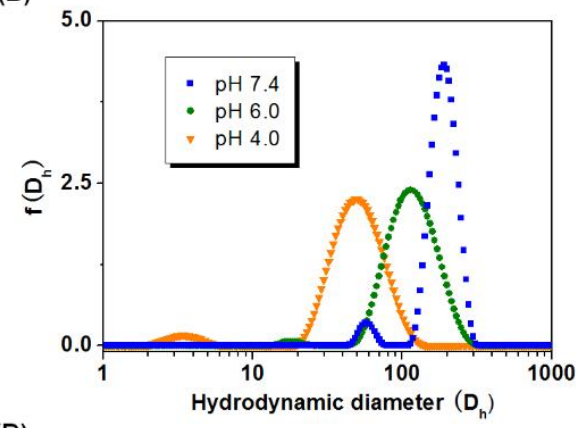

(D)

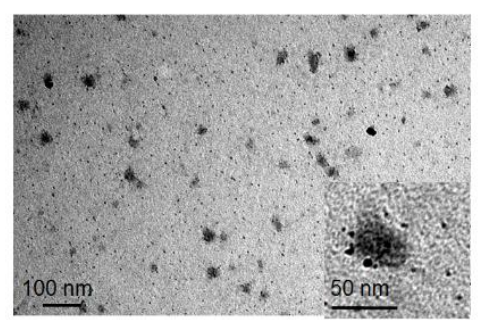

Fig. 1 (A) ${ }^{1} \mathrm{H}$ NMR spectra of $\mathrm{Lys}_{30}-\mathrm{CH}=\mathrm{N}-\mathrm{PEG}-\mathrm{NH}_{2}$ at $\mathrm{pH} 7.4$ and 6.0 in $\mathrm{D}_{2} \mathrm{O}$. (B) DLS results of LNP $\mathrm{dePEG}_{\mathrm{FA}}$ at pH values of 7.4, 6.0 and 4.0 in water. TEM images of $\mathrm{LNP}_{\text {dePEG-FA }}$ at $\mathrm{pH} 7.4$ (C) and 4.0 (D) in water.

${ }^{1} \mathrm{H}$ NMR experiments were performed to test the $\mathrm{pH}$-responsiveness of the benzoic imine bond in PEG/Lys 30 block copolymer. Fig. 1A shows that when the $\mathrm{pH}$ value was changed to 6.0, the signal at $7.8 \mathrm{ppm}$ and $\mathrm{pH} 7.4$ corresponding to the benzoic imine bond weakened by $64 \%$ accompanied by the appearance of a sharp signal at $10.1 \mathrm{ppm}$ corresponding to the benzoic anhydride. This indicated significant rupture of the benzoic imine bond at a relatively low $\mathrm{pH}$ [25]. To test whether the benzoic imine bond in LNP ${ }_{\text {dePEG-FA }}$ can be cleaved intracellularly, large

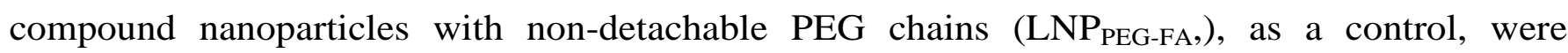
prepared under the same conditions and through the same processes as those for LNP $_{\text {dePEG-FA }}$ except that $\mathrm{NH}_{2}-\mathrm{PEG}-\mathrm{Lys}_{38}$ (Scheme S6 in SI) was used in place of $\mathrm{Lys}_{30}-\mathrm{CH}=\mathrm{N}-\mathrm{PEG}-\mathrm{NH}_{2}$. The

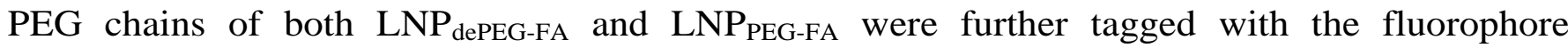
Rhodamine B isothiocyanate (RBITC; see Section 7 in SI for experimental details). For either

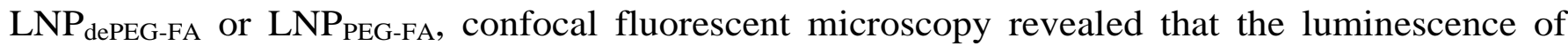
RBITC (orange) from PEG was highly correlated with the luminescence from $\operatorname{Ir}(\mathrm{dfppy})_{2}{ }^{+}$(cyan) after $0.5 \mathrm{~h}$ incubation in HeLa cells (Fig. S3 in SI). After prolonging the incubation time to $2 \mathrm{~h}$, a significant phase separation between PEG and $\operatorname{Ir}(\mathrm{dfppy})_{2}{ }^{+}$was observed for $\mathrm{LNP}_{\text {dePEG-FA }}$ (Fig. 2A), whereas the luminescence of RBITC from PEG still highly overlapped with that from $\operatorname{Ir}(\mathrm{dfppy})_{2}{ }^{+}$for LNP $\mathrm{PEG}_{\mathrm{FA}}$ (Fig. 2B). These results indicate the rupture of benzoic imine bond and detachment of PEG chains for $\mathrm{LNP}_{\text {dePEG-FA }}$ in the intracellular environment.

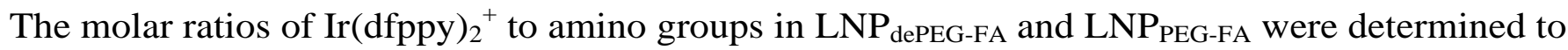
be 4.6 : 30 and 5.8 : 38 by ICP-MS, leaving $c a$. $70 \%$ unreacted $-\mathrm{NH}_{2}$ groups (Table $\mathrm{S} 1$ in SI). TEM observation revealed that the LNP $_{\text {dePEG-FA }}$ and LNP $P_{\text {PEG-FA }}$ formed in water at $\mathrm{pH} 7.4$ were 
spherical particles sized approximately 150 and $175 \mathrm{~nm}$, respectively (Fig. 1C and Fig. S2B in SI). The average hydrodynamic diameters of $\mathrm{LNP}_{\text {dePEG-FA }}$ and $\mathrm{LNP}_{\text {PEG-FA }}$ in water at $\mathrm{pH} 7.4$ was measured by DLS to be $170 \mathrm{~nm}$ and $196 \mathrm{~nm}$, respectively, which are close to the results of the TEM observations (Fig. 1B and Fig. S2A in SI). However, when the $\mathrm{pH}$ gradually decreased to 4.0, the average hydrodynamic diameter of LNP dePEG-FA $_{\text {and LNP }}$ PEG-FA decreased significantly (Fig. 1B and Fig. S2A in SI) and the sizes became ca. 40 and $45 \mathrm{~nm}$, respectively (Fig. 1D and Fig. S2C in SI). Previous studies on poly- $L$-Lys based nanoparticles reported similar behaviors of size reduction at low $\mathrm{pH}^{23}$ The size reduction at low $\mathrm{pH}$ indicates the dissociation of the primary large nanoparticles. TEM observations reveal that LNP $_{\text {dePEG-FA }}$ (or LNP PEG-FA) at pH 7.4 was a large assembly of a number of super-small particles (ca. $2 \sim 5 \mathrm{~nm}$ in diameter, the insets in Fig. 1C and Fig. S2B in SI). However, when the $\mathrm{pH}$ value decreased to 4.0, smaller particle-assemblies composed of much fewer super-small particles were observed (the insets in Fig. 1D and Fig. S2C in SI). To test whether this pH-triggered dissociation could occur intracellularly, TEM images of ultrathin sections of HeLa cells incubated with LNP dePEG-FA for 0.5 and $2 \mathrm{~h}$ were recorded. The endocytosis of large nanoparticles by cancer cells at $0.5 \mathrm{~h}$ and formation of the small nanoparticles (SNPs, representing the small nanoparticles produced from the dissociation of $\left.\mathrm{LNP}_{\text {dePEG-FA }}\right)$ as well as their escape from endo/lysosome at $2 \mathrm{~h}$ were observed (Fig. 2C and 2D).

To understand the mechanism for the formation and dissociation of the large particles, zeta potential measurements were performed at $\mathrm{pH}$ 7.4 4.0. The results revealed that both LNP $_{\text {dePEG-FA }}$ and LNP ${ }_{\text {PEG-FA }}$ became more and more positively charged with decreasing the $\mathrm{pH}$ values, and the positive charge became significant at $\mathrm{pH}$ 5.0 4.0 (Table S2 in SI). This suggests that the deprotonation of the amino groups in LNP dePEG-FA (or LNP $_{\text {PEG-FA }}$ ) was facilitated at high pH [26] and the protonation degree became significantly higher at low $\mathrm{pH}$ [27]. The higher degree of protonation at low $\mathrm{pH}$ makes the oligo-L-Lys segments more hydrophilic and more electrostatically repelling to each other, leading to the dissociation of the large particle assemblies into the small particle assemblies. More importantly, when SNP (or SNP PEG-FA, representing the small nanoparticles produced from the dissociation of LNP $_{\text {PEG-FA }}$ ) escaped from the endo/lysosomes ( $\mathrm{pH}$ 6.0 4.0) into the cytosol ( $\mathrm{pH} \sim 7.4$ ), the nanoparticles were nearly non-charged but their size remained small (Fig. 2D). This suggests that the large nanoparticles $\left(\mathrm{LNP}_{\mathrm{dePEG}-\mathrm{FA}}\right.$ and LNP $\left.\mathrm{PEG}_{\mathrm{PA}}\right)$ were large compound nanoparticles formed in a kinetically-controlled fashion due to the abrupt adding of neutral water and fast assembly of the particles [28,29]. The kinetically controlled process leads to encapsulation of hydrophilic Lys moieties, resulting in the large size. At low $\mathrm{pH}$, the amino groups from oligo- $L$-Lys segments in SNP that were kinetically encapsulated within the primary large compound nanoparticles are now 
exposed to water and become protonated to stabilize the small nanoparticles. Although the $\mathrm{pH}$ value was changed back to $\sim 7.4$, the hydrophilic nature of the amino groups helped to prevent the small nanoparticles from re-aggregating into large nanoparticles.

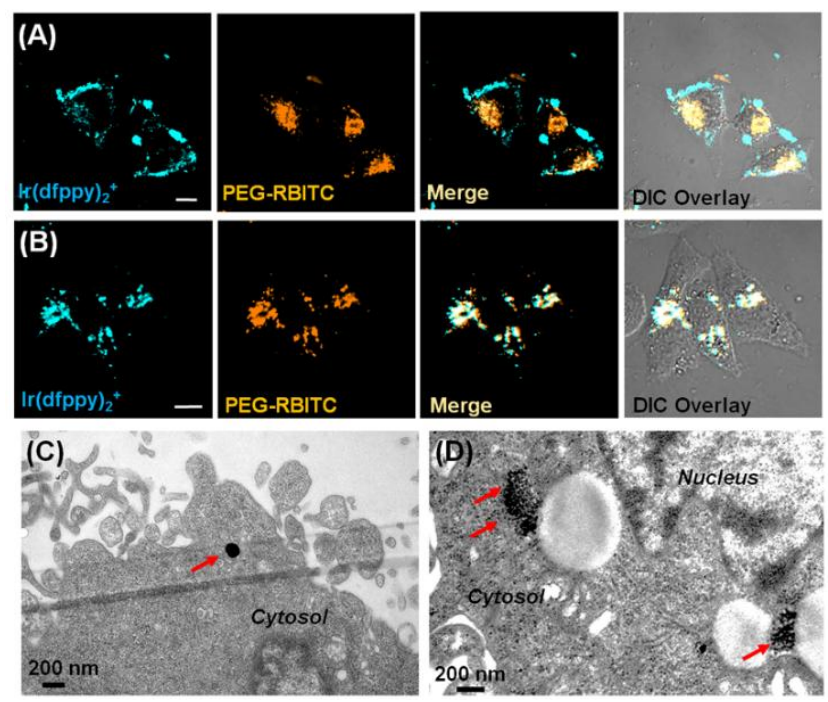

Fig. 2 Confocal luminescence images of HeLa cells incubated with (A) LNP dePEG-FA $_{\text {or }(B) ~ L N P}$ PEG-FA (Ir: $2.0 \mathrm{mg} / \mathrm{L}$ ) for $2.0 \mathrm{~h}$ at 37 ${ }^{\circ} \mathrm{C}$ (for RBITC: $\lambda_{\mathrm{ex}}=543 \mathrm{~nm}, \lambda_{\mathrm{em}}=555-620 \mathrm{~nm}$; for $\operatorname{Ir}(\mathrm{dfppy})_{2}{ }^{+}, \lambda_{\mathrm{ex}}=405 \mathrm{~nm}, \lambda_{\mathrm{em}}=450-490 \mathrm{~nm}$ ). TEM images of ultrathin sections of HeLa cells incubated with $\mathrm{LNP}_{\text {dePEG-FA }}$ for $0.5 \mathrm{~h}(\mathrm{C})$ and $2 \mathrm{~h}$ (D) at $37{ }^{\circ} \mathrm{C}$. Red arrows indicate nanoparticles at different time points.

\section{Nuclear entry of the nanoparticles via the nucleopore}

Flow cytometry was then applied for analysis of FA targeting effect of the nanoparticle $\mathrm{LNP}_{\text {dePEG-FA. }}$ The results showed that cellular uptake of $\mathrm{LNP}_{\text {dePEG-FA }}$ was significantly inhibited when free FA was added to the culture medium (Fig. S9 in SI). This result indicated that the cellular uptake of $\mathrm{LNP}_{\text {dePEG-FA }}$ was mediated via FA-FA receptor interaction and thus confirmed

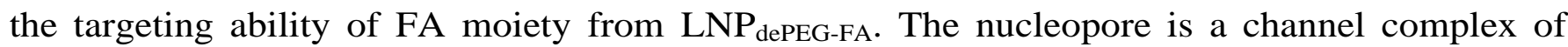
proteins which can allow access of nanoparticles up to $50 \mathrm{~nm}$ [9a,12]. The small sizes of the dissociated nanoparticles (i.e. SNP and SNP PEG-FA) due to the aforementioned

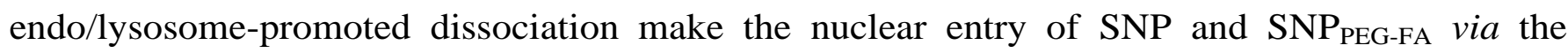
nucleopore possible. As mentioned before, after entry into the cytosol, most of the PEG shield detached from SNP and the oligo-L-lysine segments were exposed (Fig. 2A) while SNP PEG-FA $_{\text {was }}$ still fully shielded by the PEG chains on the surface since the PEG chains in SNP $_{\text {PEG-FA }}$ cannot be detached (Fig. 2B). To investigate the impact of PEG chains on the nuclear entry of the nanoparticles, LNP $_{\text {dePEG-FA }}$ and LNP PEG-FA were separately incubated with HeLa cells. As shown in Fig. 3A, after $6 \mathrm{~h}$ incubation, an intense luminescence from $\mathrm{LNP}_{\text {dePEG-FA }}$ appeared in the nuclear regions of HeLa cells (Fig. S5 A in SI). Besides, most of the PEG chains detached from the nanoparticles and were sequestrated within the endo/lysosomes as confirmed by the co-localization of a commercial endo/lysosomal stain Lyso Tracker Deep Red ${ }^{\circledR}$ (red). The 
significantly high overlap ratio (> 70\%) between PEG chains and the endo/lysosomes confirmed that PEG detachment took place within the endo/lysosomes. In contrast, LNP PEG-FA was only sequestered in the cytosol even after $12 \mathrm{~h}$ incubation with HeLa cells (Fig. S4 in SI).

The inability of $\left[\operatorname{Ir}(\mathrm{dfppy})_{2} \mu-\mathrm{Cl}\right]_{2}$ to enter the nucleus excludes the possibility that unreacted $\left[\operatorname{Ir}(\mathrm{dfppy})_{2} \mu-\mathrm{Cl}\right]_{2}$ molecules encapsulated in the particles would be able to diffuse out and translocate into the nucleus [24h]. Furthermore, the PEG chains on the surface of LNP PEG-FA $_{\text {. }}$ appeared to inhibit the nuclear entry of the nanoparticles. This indicates the importance of the exposed oligo- $L$-lysine outside the nanoparticles for nuclear entry. Taken together, these results indicate that the native drug $\left[\operatorname{Ir}(\mathrm{dfppy})_{2} \mu-\mathrm{Cl}\right]_{2}$ was not capable of entering the nucleus unassisted

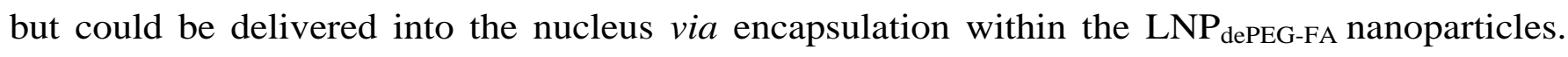
This was also confirmed by dual-channel luminescence imaging, where oligo-L-lysine was tagged with the fluorophore RBITC (Section 7 in SI for experimental details). After $6 \mathrm{~h}$ incubation, there was ca. $84 \%$ of overlap between RBITC (orange) and $\operatorname{Ir}(\mathrm{dfppy})_{2}{ }^{+}$(cyan) in regions of the nucleus (Fig. 3B and Fig. S5B in SI). According to the confocal fluorescent microscopy observations, SNP entered the nucleus of nearly all HeLa cells after $6 \mathrm{~h}$ incubation and no cell mitosis was observed during the observations. It is known that the mitosis period for HeLa cells is $c a$. $21 \mathrm{~h}$ [30]. If the nuclear entry had occurred during cell division, the nanoparticles would not have entered the nuclei of all the HeLa cells after the $6 \mathrm{~h}$ incubation. Therefore, it can be concluded that SNP entered the nucleus via the nucleopore. To further demonstrate this, ultrathin sections of

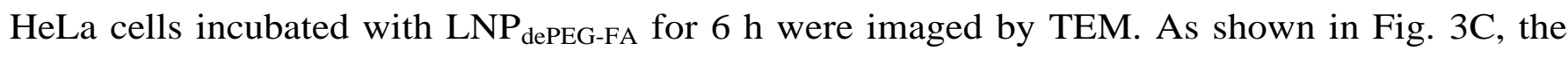
nuclear entry of the nanoparticles via the nucleopore (as indicated by red arrows) and the nuclear localization (as indicated by red dashed circles) of the nanoparticles were observed. Some nanoparticles were even located within the nucleolus after incubation (as indicated by red dashed circles in the right panel in Fig. 3C), which may have resulted from the interaction between the oligo- $L$-Lys of SNP and intranuclear DNA.

\section{Intranuclear drug release of the nanoparticles}

As shown in Fig. 4A, after further prolonging the incubation time of HeLa cells with LNP dePEG-FA to $7 \mathrm{~h}$, only $60 \%$ of overlap between the luminescence of oligo- $L$-lysine (orange) and $\operatorname{Ir}(\mathrm{dfppy})_{2}{ }^{+}$ (cyan) was observed, which was significantly lower than the degree of overlap at $6 \mathrm{~h}$ incubation (84\%, Fig. 3B). This fact indicates significant phase separation between oligo- $L$-lysine and $\operatorname{Ir}(\mathrm{dfppy})_{2}{ }^{+}$in the nucleus after $7 \mathrm{~h}$ incubation. As previously mentioned, most of the SNP entered the nucleus of HeLa cells after $6 \mathrm{~h}$ incubation and thus the phase separation took place after the nuclear entry of the nanoparticles. The phase separation suggests that the $\operatorname{Ir}(\mathrm{dfppy})_{2}{ }^{+}$moieties 
were significantly released from SNP into the nucleus. The intranuclear drug release was further confirmed by the real-time observation of the intranuclear nanoparticles, as recorded by confocal fluorescent microscopy in 10-min intervals for $40 \mathrm{~min}$ after $6 \mathrm{~h}$ incubation. It was found that the luminescence intensity of $\operatorname{Ir}(\mathrm{dfppy})_{2}{ }^{+}$was progressively enhanced over time (red line in Fig. 4B). Meanwhile, the overlap ratio between $\operatorname{Ir}(\mathrm{dfppy})_{2}{ }^{+}$and oligo- $L$-lysine intranuclearly decreased gradually (blue line in Fig. 4B).

(A)

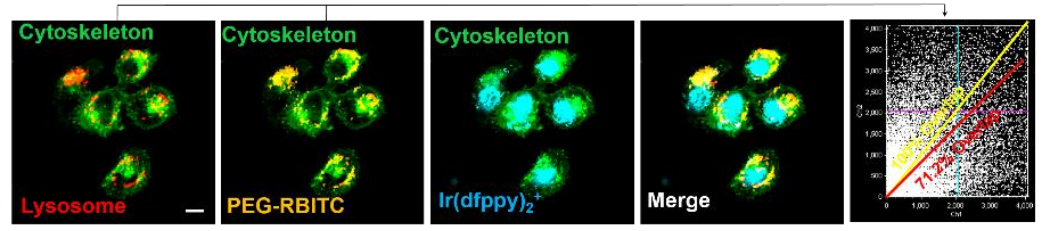

(B)

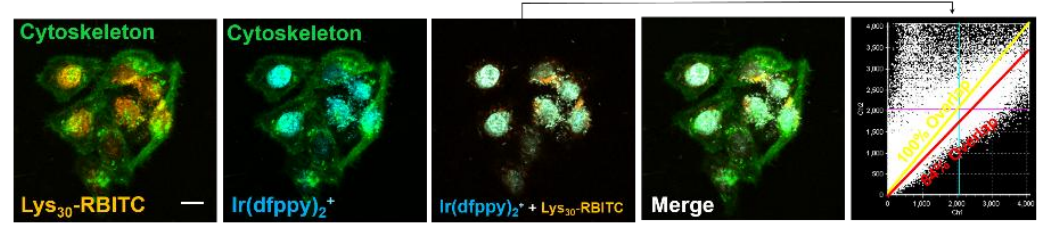

(C)

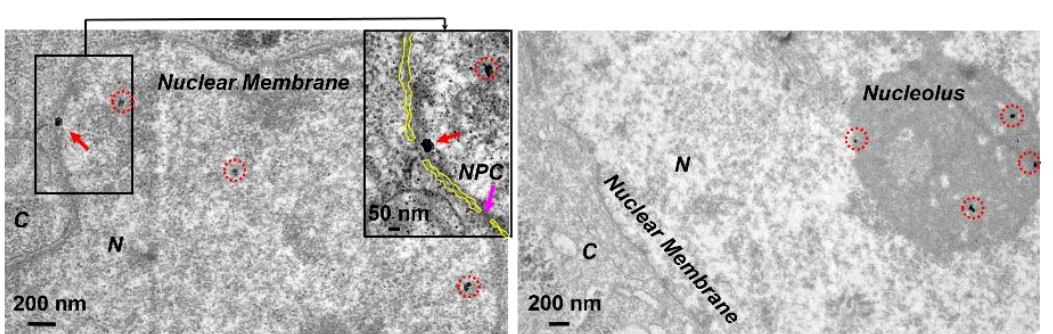

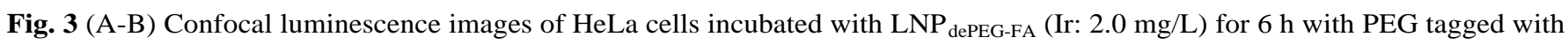
RBITC (A) and oligo- $L$-lysine tagged with RBITC (B), respectively (for RBITC: $\lambda_{\mathrm{ex}}=543 \mathrm{~nm}, \lambda_{\mathrm{em}}=555-620 \mathrm{~nm}$; for Ir(dfppy) ${ }_{2}^{+}$, $\lambda_{\mathrm{ex}}=405 \mathrm{~nm}, \lambda_{\mathrm{em}}=450-490 \mathrm{~nm}$; for Dio, $\lambda_{\mathrm{ex}}=488 \mathrm{~nm}, \lambda_{\mathrm{em}}=500-550 \mathrm{~nm}$; For Lyso Tracker Deep Red, $\lambda_{\mathrm{ex}}=633 \mathrm{~nm}, \lambda_{\mathrm{em}}=$ 660-750 nm). The white scale bars represent $10 \mu \mathrm{m}$. (C) TEM images of ultrathin sections of HeLa cells incubated with $\mathrm{LNP}_{\text {dePEG-FA }}$ for $6 \mathrm{~h}$, showing that SNP enters the nucleus via nucleopores (indicated by the red arrows) and the nuclear localization of SNP (indicated by the red dashed circles). The pink arrow indicates a nuclear pore complex (NPC).

Through screening the interactions between the $\operatorname{Ir}(\mathrm{III})$ complex and 20 different natural amino acids in vitro, our and other previous reports showed that only histidine can interact with $\operatorname{Ir}(\mathrm{dfppy})_{2}{ }^{+}$due to the relatively strong interaction between the imidazolyl groups and $\operatorname{Ir}(\mathrm{dfppy})_{2}{ }^{+}$, which resulted in a significant enhancement in luminescence emission [19]. Thus, the luminescence enhancement in the real-time luminescence observation suggests that $\operatorname{Ir}(\mathrm{dfppy})_{2}{ }^{+}$ interacted with histidine residues in the nucleus. To confirm this hypothesis, calf thymus DNA ( $c t$-DNA) and nuclear protein extracts of HeLa cells were incubated with SNP. Ethidium bromide (EB) was used as a fluorescent dye for DNA [31]. It was found that the fluorescence intensity increments of EB in EB/ct-DNA/SNP mixtures were significantly lower than those in EB/ct-DNA (Fig. S6 in SI), indicating prohibition of the EB insertion by SNP. Thus SNP interacted with and possibly wrapped around DNA, which made the EB insertion difficult [32]. The results of control experiments exhibit that the fluorescent intensity of SNP was significantly enhanced in the 
mixture of SNP/ct-DNA/nuclear proteins, while it was only slightly enhanced in either the mixture of SNP/ct-DNA or the mixture of SNP/nuclear proteins (Fig. S7 in SI). Therefore, the coexistence of SNP with both DNA and nuclear proteins is necessary for the remarkable fluorescence enhancement, which is consistent with the abovementioned fact that the luminescence intensity of $\operatorname{Ir}(\mathrm{dfppy})_{2}{ }^{+}$was increased significantly in the nucleus since all the components coexist in the nucleus. Considering the fact that the imidazolyl groups can interact strongly with and thus increase significantly the luminescence intensity of $\operatorname{Ir}(\mathrm{dfppy})_{2}{ }^{+}[19]$, we believe that, in either the mixture of SNP/ct-DNA/nuclear proteins or the nucleus, the $\operatorname{Ir}(\mathrm{dfppy})_{2}{ }^{+}$ moieties interact with the nuclear proteins containing imidazolyl groups of histidine residues. This interaction between the $\operatorname{Ir}(\mathrm{dfppy})_{2}{ }^{+}$moieties and nuclear proteins should be assisted by the interaction of SNP with DNA, since it does not occur considerably in the mixture of SNP/nuclear proteins (indicated by slight increase in the luminescence intensity); the interaction between DNA and SNPs was confirmed by the abovementioned EB insertion experiment. The interaction between the $\operatorname{Ir}(\mathrm{dfppy})_{2}{ }^{+}$moieties and the nuclear proteins assisted by the SNP/DNA interaction might account for the intranuclear release of the $\operatorname{Ir}(\mathrm{III})$ complex.

\section{Intranuclear drug release inducing apoptosis of the cancer cells}

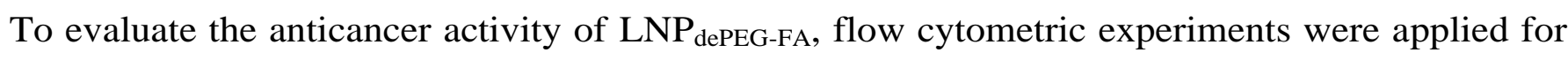

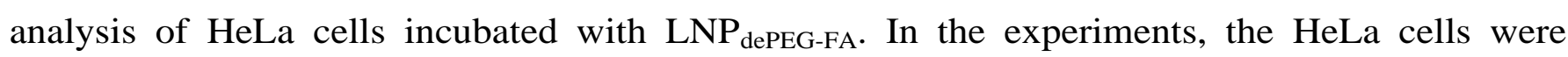
co-stained for viability and it was found that the apoptosis ratios of the cells increased with increasing the incubation time (Fig. S8 in SI). Caspase-3 is the executor of cell apoptosis and thus ELISA to determine the levels of procaspase-3 in HeLa cells was used to investigate the apoptosis in greater details. As shown in Fig. 5A, with increasing the incubation time, higher consumption levels of procaspase-3 were observed. This confirmed that procaspase-3 was converted to

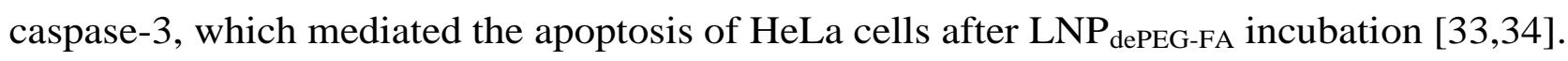


(A)
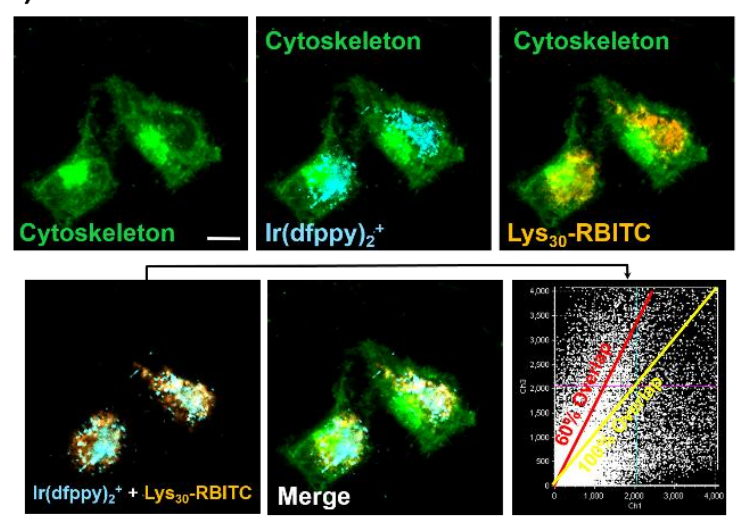

(B)

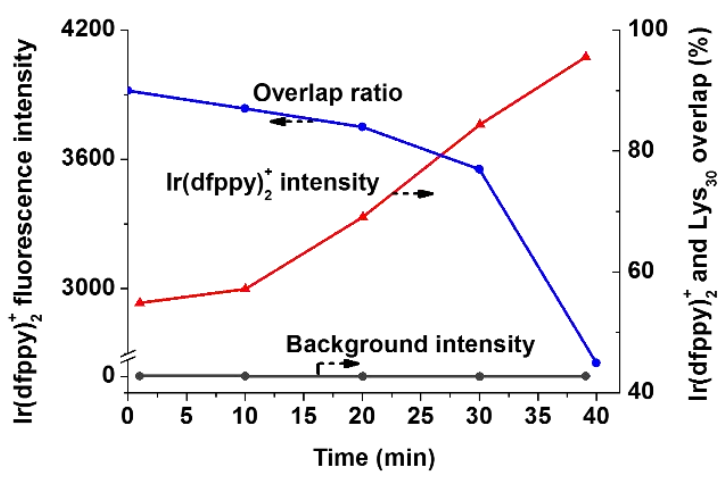

Fig. 4 (A) Confocal luminescence images of Hela cells incubated with LNP dePEG-FA $(\operatorname{Ir}: 2.0 \mathrm{mg} / \mathrm{L}$ ) for $7 \mathrm{~h}$; in the LNP dePEG-FA, oligo- $L$-lysine was tagged by RBITC (RBITC: $\lambda_{\text {ex }}=543 \mathrm{~nm}, \lambda_{\text {em }}=555-620 \mathrm{~nm} ; \operatorname{Ir}(\mathrm{dfppy})_{2}{ }^{+}, \lambda_{\text {ex }}=405 \mathrm{~nm}, \lambda_{\text {em }}=450-490 \mathrm{~nm}$; Dio, $\lambda_{\mathrm{ex}}=488 \mathrm{~nm}, \lambda_{\mathrm{em}}=500-550 \mathrm{~nm}$ ). (B) Time courses of luminescence intensity of $\operatorname{Ir}(\mathrm{dfppy})_{2}{ }^{+}$and a control background point and overlap ratios between $\operatorname{Ir}(\mathrm{dfppy})_{2}{ }^{+}$and oligo- $L$-lysine in the nucleus, as recorded by the real-time observation of intranuclear nanoparticles at 10-min intervals for $40 \mathrm{~min}$ after $6 \mathrm{~h}$ incubation. The white scale bars represent $10 \mu \mathrm{m}$.

MTT assay was performed on HeLa cells to evaluate cytotoxicity of the different drug formulations. The native drug $\left[\operatorname{Ir}(\mathrm{dfppy})_{2} \mu-\mathrm{Cl}\right]_{2}(\mathrm{~F}-\mathrm{Ir})$ was pre-dissolved in DMSO to enhance the water-solubility of the drug and determined with an $\mathrm{IC}_{50}$ value of $c a .70 \mu \mathrm{M}$ of Ir (Fig. 5B).

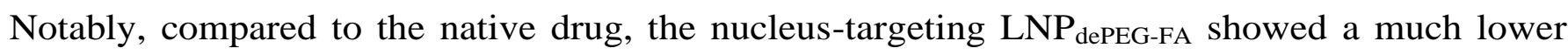
(ca. 20-fold lower) $\mathrm{IC}_{50}$ value (Fig. 5B). Such a significant difference in cytotoxicity between $\mathrm{LNP}_{\text {dePEG-FA }}$ and $\left[\operatorname{Ir}(\mathrm{dfppy})_{2} \mu-\mathrm{Cl}\right]_{2}$ could be attributed to the intranuclear delivery and release of

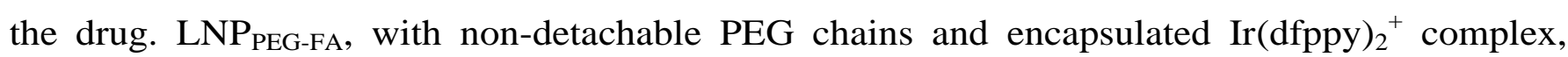
exhibited much lower cytotoxicity compared to the native drug, suggesting the protection effects from drug release by the drug-carrier. Clearly, the intranuclear release of the metallodrug provides a highly effective way to kill HeLa cells. 
(A)

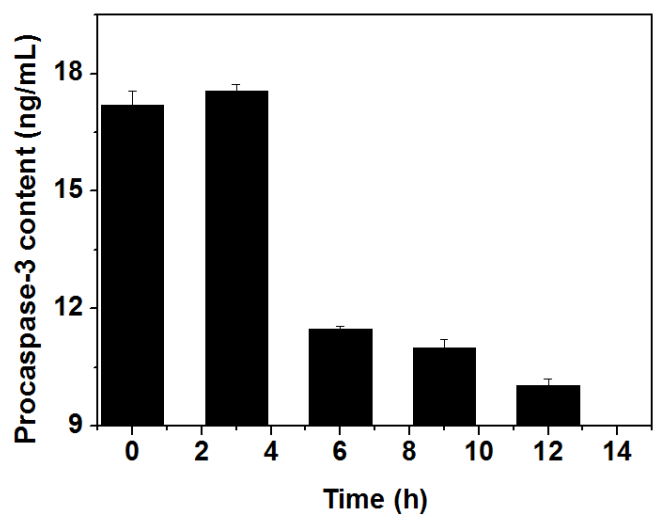

(B)

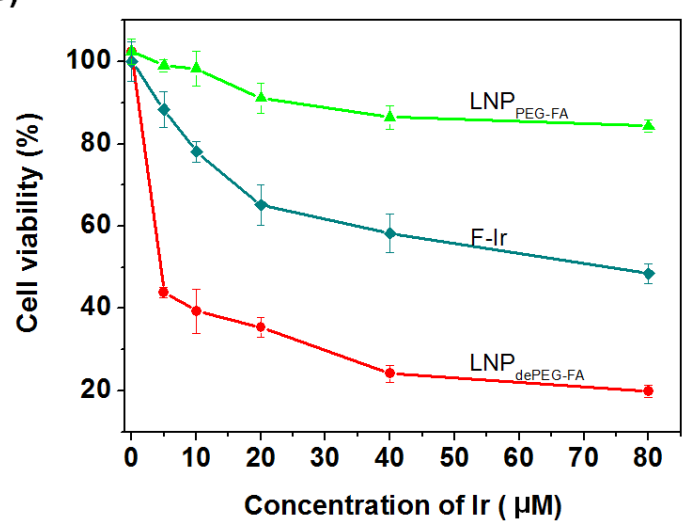

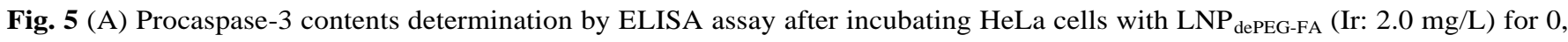
$3,6,9$, and $12 \mathrm{~h}$ at $37^{\circ} \mathrm{C}$. (B) Results of MTT assay for $48 \mathrm{~h}$ of $\mathrm{LNP}_{\text {dePEG-FA }}, \mathrm{LNP}_{\mathrm{PEG}-\mathrm{FA}}$ and the metallodrug $\left[\operatorname{Ir}(\mathrm{dfppy})_{2} \mu-\mathrm{Cl}\right]_{2}$ on HeLa cells. (Data are mean $\pm \mathrm{SD}, \mathrm{n}=3$, * $\mathrm{p}<0.05$ ).

\section{In vivo tumoral uptake and nucleus-targeted drug delivery}

For the in vivo studies, an A549-cell-xenografted female nude mouse model was established and the mice received an intravenous injection of different drug formulations. As a control, the nanoparticles of $\mathrm{Lys}_{30} / \mathrm{Ir}(\mathrm{III})$ complex were prepared under the same conditions and through the same processes as those for LNP $_{\text {dePEG-FA }}$ except that oligo- $L$-Lys (Lys ${ }_{30}$ ) was used in place of Lys $_{30}-\mathrm{CH}=\mathrm{N}-\mathrm{PEG}-\mathrm{NH}_{2}$. The as-prepared Lys $30 / \mathrm{Ir}(\mathrm{III})$ nanoparticles are spherical large compound nanoparticles comparable to $\mathrm{LNP}_{\text {dePEG-FA }}$ in size, morphology and inner structure, but without the PEG decoration [20c]. The in vivo uptake of nanoparticles by tumor tissues as well as by other organs was investigated and determined by ICP-MS. Compared to Lys $30 / \mathrm{Ir}$ (III) nanoparticles,

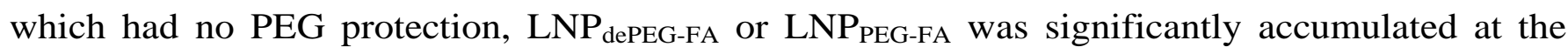
tumor sites (Fig. 6A). ICP-MS was used to monitor blood clearance of the nanoparticles. The results showed that $\mathrm{Lys}_{30} / \mathrm{Ir}$ (III) nanoparticles were rapidly cleared from the bloodstream, whereas $\mathrm{LNP}_{\text {dePEG-FA }}$ or LNP $\mathrm{PEG}_{\text {PEA }}$ with PEG protection from non-specific interactions exhibited a much longer blood circulation time (Fig. S10 in SI). The prolonged blood circulation time of

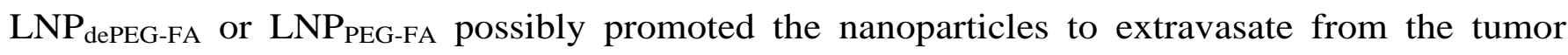
blood vessels into the tumor tissues via the EPR effect [18,35]. It has to be mentioned here that, 
during the in vivo application, the benzoic imine bond may rupture and PEG chains would thus detach in the acidic tumor extracellular microenvironment ( $\mathrm{pH}$ 6.4 6.8) since the imine bond ruptures at $\mathrm{pH} 6.5$ [25]. This should promote the cellular uptake of the nanoparticles and thus benefit the cancer therapy.

(A)

(B)
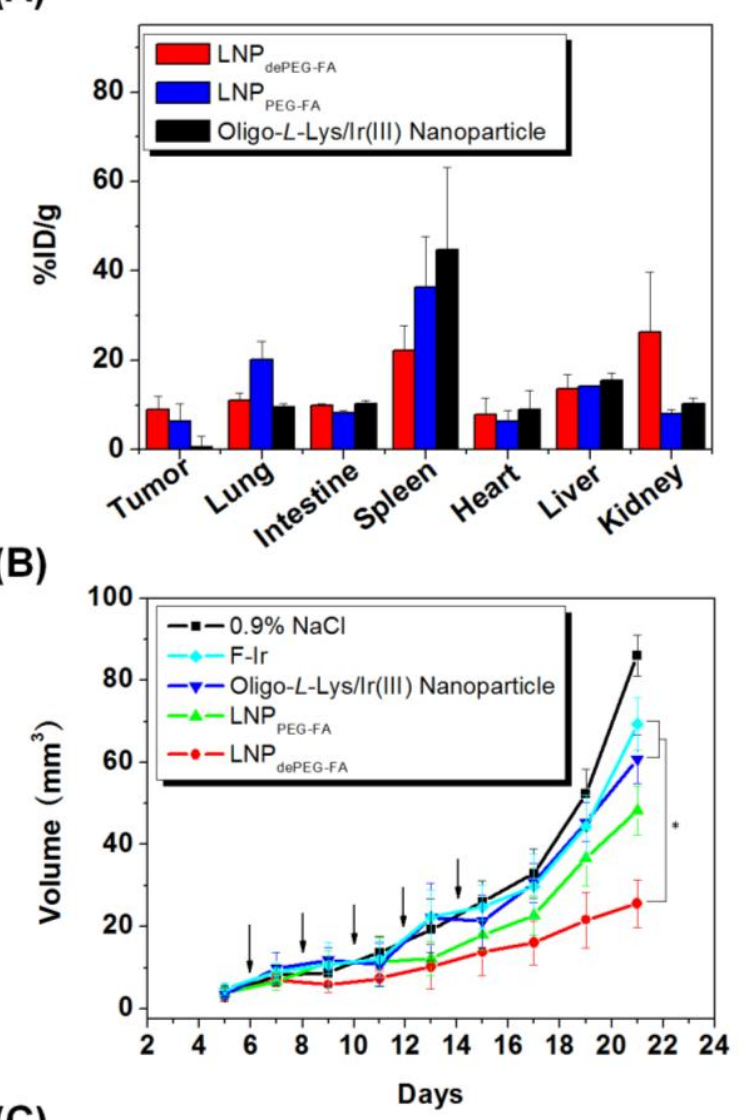

(C)

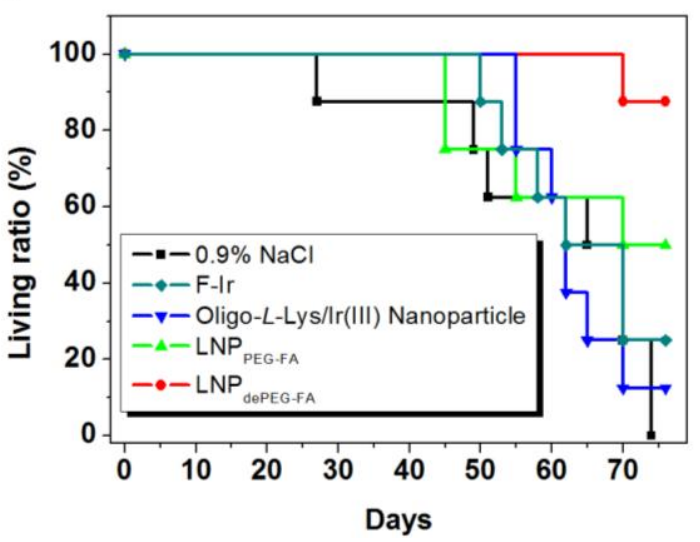

Fig. 6 (A) In vivo uptake of $\mathrm{Lys}_{30} / \mathrm{Ir}(\mathrm{III})$ nanoparticles, $\mathrm{LNP}_{\text {PEG-FA }}$ or $\mathrm{LNP}_{\text {dePEG-FA }}$ by tumor tissues and other organs after $24 \mathrm{~h}$ of a single injection at a dose of $2.0 \mathrm{mg} / \mathrm{kg}$ of $\mathrm{Ir}$ equivalent $(\mathrm{n}=3$, data are mean $\pm \mathrm{SD}, * \mathrm{p}<0.05)$. (B) Anti-tumor efficacy and (C) life-span monitoring tests of different drug formulations at a dose of $10 \mathrm{mg} / \mathrm{kg}$ of $\mathrm{Ir}$ equivalents for five times, as indicated by the black arrows. Tumors were measured every second day and the tumor volume was calculated accordingly ( $\mathrm{n}=8$, data are mean \pm $\mathrm{SD}, * \mathrm{p}<0.01)$

The in vivo anti-tumor efficacy of LNP $_{\text {dePEG-FA }}$ was further assessed on the mouse model (Fig. 6B and 6C and Section 12 in SI for experimental details). The tumor growth of mice treated with 
$\mathrm{LNP}_{\text {dePEG-FA }}$ was much slower than that of mice treated with $\mathrm{LNP}_{\text {PEG-FA, }}$ Lys $\mathrm{S}_{30} / \mathrm{Ir}$ (III) nanoparticles or the native drug $\left[\operatorname{Ir}(\mathrm{dfppy})_{2} \mu-\mathrm{Cl}\right]_{2}$, and the difference became significant $(\mathrm{p}<0.05)$ after day 17. Tumor-inhibition rate (TIR) was then calculated based on the tumor volumes using a previously reported equation [36]. A $70 \%$ of TIR was found in mice treated with LNP $_{\text {dePEG-FA, compared }}$ with TIRs of 19, 29 and $44 \%$ for $\left[\operatorname{Ir}(\mathrm{dfppy})_{2} \mu-\mathrm{Cl}\right]_{2}, \mathrm{Lys}_{30} / \operatorname{Ir}(\mathrm{III})$ nanoparticles and LNP $\mathrm{PEG}_{\text {-FA, }}$ respectively (Fig. 6B). The greater tumor inhibition achieved by $\mathrm{LNP}_{\text {dePEG-FA }}$ could be attributed to the enhanced tumoral uptake and nuclear delivery of the potential anticancer drug. More importantly, mice treated with LNP $_{\text {dePEG-FA }}$ showed notably greater life-span enhancement compared to other groups (Fig. 6C). Furthermore, the mice treated with LNP dePEG-FA $_{\text {showed no }}$ body loss during the treatment (Fig. S11 in SI). These suggest that LNP $_{\text {dePEG-FA }}$ might function as a novel nano-platform for chemotherapy with limited physiological toxicity [18].

The antitumor mechanism of the nucleus-targeted metallodrug delivery of LNP dePEG-FA was further analyzed by histological examinations. As determined by hematoxylin/eosin (H\&E) staining, the tumor cells in mice treated with $0.9 \% \mathrm{NaCl},\left[\operatorname{Ir}(\mathrm{dfppy})_{2} \mu-\mathrm{Cl}\right]_{2}$ or $\operatorname{Lys} 30 / \operatorname{Ir}(\mathrm{III})$ nanoparticles (Fig. 7A-C and the insets) showed relatively full and complete cytoplasm or nuclei,

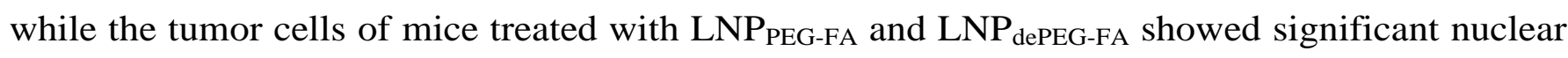
cavitation (Fig. 7D and the inset) and condensation (Fig. 7E and the inset), respectively. Deformation of the nucleus is a typical sign of apoptotic cells [18,37]. Indeed, terminal deoxynucleotidyl transferase dUTP nick end labeling (TUNEL) staining revealed significant

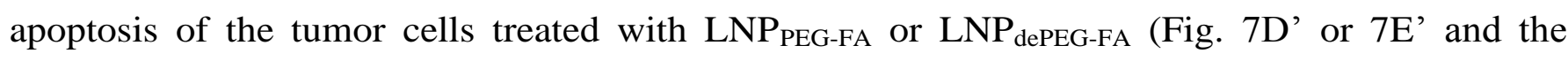
insets). In comparison, the tumor cells treated with other drug formulations were negative in the TUNEL assay (Fig. 7A' $\mathrm{C}^{\prime}$ ). These results suggest that the tumor suppression in vivo by LNP $_{\text {dePEG-FA }}$ was achieved by eliciting apoptosis of the tumor cells, which was consistent with the results from the in vitro cell studies.

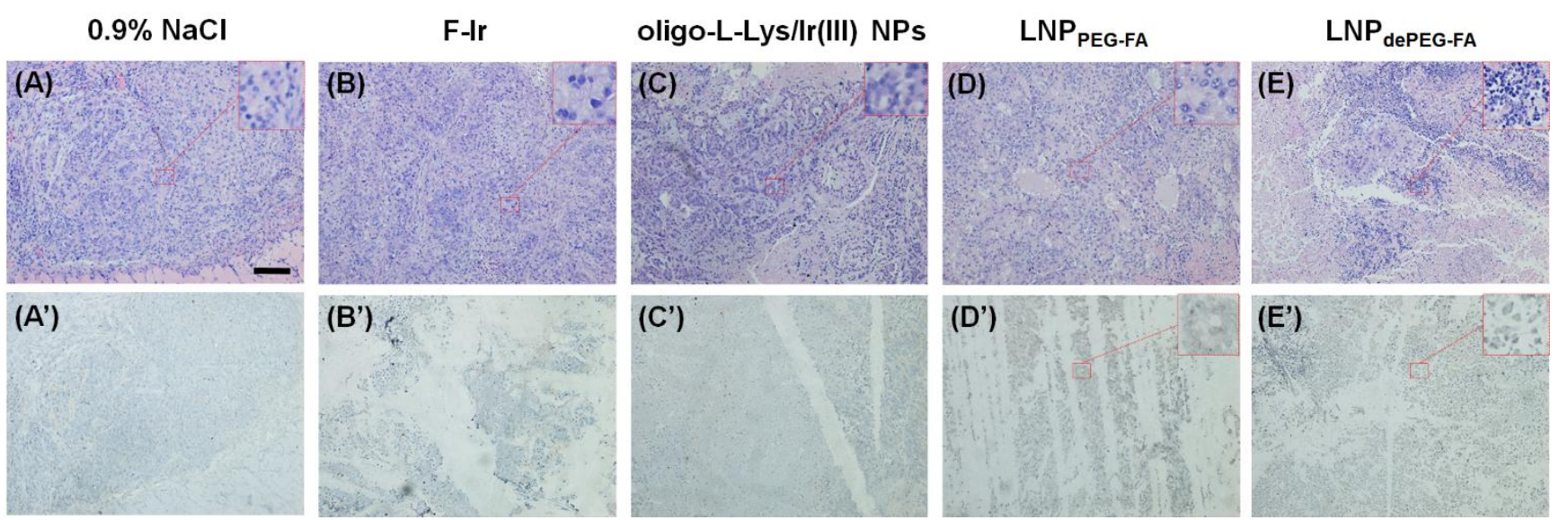

Fig. 7. Light microscopy images of (A-E) hematoxylin/eosin (H\&E) and (A'-E') TdT-mediated dUTP nick end labeling (TUNEL) staining of tumor sections of the mice after treatments. In the pictures A-E, the assay was used to characterize the morphologies of 
the cytoplasm and the nucleus. In (A'-E'), the assay was used to determine the apoptotic cells which are identified by positive TUNEL staining (brown) under light microscopy. The scale bar represents $200 \mu \mathrm{m}$.

\section{Conclusions}

We have prepared and demonstrated the large compound nanoparticle $\left(\mathrm{LNP}_{\mathrm{dePEG}-\mathrm{FA}}\right)$ of PEG-benzoic imine-oligo- $L$-lysine/iridium(III) metallodrug complex as a nanosystem for nucleus-targeted drug delivery in vitro and in vivo. LNP $_{\text {dePEG-FA }}$ simultaneously addresses the contradictory requirements for size and surface property of nuclear entry vehicles from blood to the intracellular nucleus. Initially, the large size of $\mathrm{LNP}_{\text {dePEG-FA }}$ helps to avoid systematic toxicity of the nanoparticle. However, the large nanoparticle dissociates into smaller entities when they are endocytosed into acidic endo/lysosomes. The PEG chains initially bound to the large particle protect the nanoparticle from non-specific interactions in the vascular environment, but they become detached in the acidic interior of endo/lysosomes. After dissociation and PEG detachment of $\mathrm{LNP}_{\text {dePEG-FA, }}$, the resultant smaller nanoparticles can actively translocate into the nucleus via the nucleopore. $\mathrm{LNP}_{\text {dePEG-FA }}$ showed $c a$. 20-fold higher cytotoxicity in vitro and greater tumor suppression in a mice model compared to the native drug. We believe that this work would stimulate a wide array of nanosystems directed toward in vivo nucleus-targeted drug delivery. 


\section{Acknowledgements}

National Science Foundation of China (21231004, 21334001 and 21574025), the Ministry of Science and Technology of China (2015CB931800 and 2012CB932403), The CAS/SAFEA International Partnership Program for Creative Research Teams were acknowledged for funding this research.

Supplementary Data synthesis methods and NMR characterization data for the compounds; preparation and characterization of the nanoparticles; confocal microscopy images of nuclear entry of the nanoparticles; molecular analysis of apoptotic cells in vitro; in vivo blood circulation time and changes of mice body weights during the treatment.

\section{References}

[1] D. Peer, J. M. Karp, S. Hong, O. C. FaroKHzad, R. Margalit, R. Langer, Nanocarriers as an emerging platform for cancer therapy, Nat. Nanotechnol., 2007, 2, 751.

[2] M. Ferrari, Cancer nanotechnology: opportunities and challenges, Nat. Rev. Cancer, 2005, $5,161$.

[3] M. H. Sui, W. W. Liu, Y. Q. Shen, Nuclear drug delivery for cancer chemotherapy, $J$. Control Release, 2011, 155, 227.

[4] P. S. Xu, E. A. Van Kirk, Y. H. Zhan, W. J. Murdoch, M. Radosz, Y. Q. Shen, Targeted charge-reversal nanoparticles for nuclear drug delivery, Angew. Chem. Int. Edit., 2007, 46, 4999.

[5] J. H. Gao, G. L. Liang, B. Zhang, Y. Kuang, X. X. Zhang, B. Xu, FePt@CoS $\operatorname{Col}_{2}$ yolshell nanocrystals as a potent agent to kill HeLa cells, J. Am. Chem. Soc., 2007, 129, 1428.

[6] M. Duvvuri, J. P. Krise, Intracellular drug sequestration events associated with the emergence of multidrug resistance: a mechanistic review, Front. Biosci., 2005, 10, 1499.

[7] (a) Z. X. Zhou, Y. Q. Shen, J. B. Tang, M. H. Fan, E. A. Van Kirk, W. J. Murdoch, M. Radosz, Charge-reversal drug conjugate for targeted cancer cell nuclear drug delivery, Adv. Funct. Mater., 2009, 19, 3580. (b) O. Aronov, A. T. Horowitz, A. Gabizon, M. A. Fuertes, J. M. Perez, D. Gibson, Nuclear localization signal-targeted poly(ethylene glycol) conjugates as potential carriers and nuclear localizing agents for carboplatin analogues, Bioconjugate Chem., 2004, 15, 814. (c) A. Jana, B. Saha, D. R. Banerjee, S. K. Ghosh, K. T. Nguyen, X. Ma, Q. Qu, Y. Zhao, N. D. P. Singh, Photocontrolled nuclear-targeted drug 
delivery by single component photoresponsive fluorescent organic nanoparticles of acridin-9-methanol, Bioconjugate Chem., 2013, 24, 1828. (d) F. Porta, G. E. M. Lamers, J. Morrhayim, A. Chatzopoulou, M. Schaaf, H. D. Dulk, C. Backendorf, J. I. Zink, A. Kros, Folic acid-modified mesoporous silica nanoparticles for cellular and nuclear targeted drug delivery. Adv. Healthc. Mater., 2013, 2, 281.

[8] V. Cepeda, M. A. Fuertes, J. Castilla, C. Alonso, C. Quevedo, J. M. Perez, Biochemical mechanisms of cisplatin cytotoxicity, Anti-cancer Agents Me., 2007, 7, 3.

[9] (a) L. M. Pan, Q. J. He, J. N. Liu, Y. Chen, M. Ma, L. L. Zhang, J. L. Shi, Nuclear-targeted drug delivery of TAT peptide-conjugated monodisperse mesoporous silica nanoparticles, J. Am. Chem. Soc., 2012, 134, 5722. (b) J. N. Liu, W. B. Bu, L. M. Pan, S. Zhang, F. Chen, L. P. Zhou, K. L. Zhao, W. J. Peng, J. L. Shi, Simultaneous nuclear imaging and intranuclear drug delivery by nuclear-targeted multifunctional upconversion nanoprobes, Biomaterials, 2012, 33, 7282. (c) S. Barua, S. Mitragotri, Synergistic targeting of cell membrane, cytoplasm, and nucleus of cancer cells using rod-shaped nanoparticles, ACS Nano, 2013, 7, 9558. (d) Y. Yuan, S. Chen, T. Paunesku, S. C. Gleber, W. C. Liu, C. B. Doty, R. Mak, J. Deng, Q. Jin, B. Lai, K. Brister, C. Flachenecker, C. Jacobsen, S. Vogt, G. E. Woloschak, Epidermal growth factor receptor targeted nuclear delivery and high-resolution whole cell X-ray imaging of $\mathrm{Fe}_{3} \mathrm{O}_{4} @ \mathrm{TiO}_{2}$ nanoparticles in cancer cells, ACS Nano, 2013, 7, 10502. (e) S. Patel, D. Jung, P. T. Yin, P. Carlton, M. Yamamoto, T. Bando, H. Sugiyama, K. B. Lee, Nanoscript: a nanoparticle-based artificial transcription factor for effective gene regulation, ACS Nano, $2014,8,8959$.

[10] (a) J. S. Mincer, S. M. Simon, Simulations of nuclear pore transport yield mechanistic insights and quantitative predictions, Proc. Natl. Acad. Sci. USA, 2011, 108, E351. (b) S. Huo, S. Jin, X. Ma, X. Xue, K. Yang, A. Kumar, P. C. Wang, J. Zhang, Z. Hu, X. J. Liang, Ultrasmall gold nanoparticles as carriers for nucleus-based gene therapy due to size-dependent nuclear entry, ACS Nano, 2014, 8, 5852.

[11] E. Grossman, O. Medalia, M. Zwerger, Functional architecture of the nuclear pore complex, Annu. Rev. Biophys., 2012, 41, 557.

[12] Z. Li, K. Dong, S. Huang, E. Ju, Z. Liu, M. Yin, J. Ren, X. Qu, A smart nanoassembly for multistage targeted drug delivery and magnetic resonance imaging, Adv. Funct. Mater., 2014, 24, 3612.

[13] C. Zhou, M. Long, Y. P. Qin, X. K. Sun, J. Zheng, Luminescent gold nanoparticles with efficient renal clearance, Angew. Chem. Int. Edit, 2011, 50, 3168.

[14] (a) A. H. Faraji, P. Wipf, Nanoparticles in cellular drug delivery, Bioorgan. Med. Chem., 2009, 17, 2950. (b) D. S. Kohane, Microparticles and nanoparticles for drug delivery, Biotechnol. Bioeng., 2007, 96, 203. 
[15] Y. Hu, M. T. Haynes, Y. Wang, F. Liu, L. Huangy, A highly efficient synthetic vector: nonhydrodynamic delivery of DNA to hepatocyte nuclei in vivo, ACS Nano, 2013, 7, 5376.

[16] L. M. Pan, J. N. Liu, Q. J. He, J. L. Shi, MSN-mediated sequential vascular-to-cell nuclear-targeted drug delivery for efficient tumor regression, Adv. Mater., 2014, 26, 6742.

[17] (a) L. M. Pan, J. N. Liu, J. L. Shi, Intranuclear photosensitizer delivery and photosensitization for enhanced photodynamic therapy with ultralow irradiance, $A d v$. Funct. Mater., 2014, 24, 7318. (b) M. Y. Wu, Q. S. Meng, Y. Chen, Y. Y. Du, L. X. Zhang, Y. P. Li, L. L. Zhang, J. L. Shi, Large-pore ultrasmall mesoporous organosilica nanoparticles: micelle/precursor co-templating assembly and nuclear-targeted gene delivery, Adv. Mater., 2014, 27, 215.

[18] E. L. Jin, B. Zhang, X. R. Sun, Z. X. Zhou, X. P. Ma, Q. H. Sun, J. B. Tang, Y. Q. Shen, E. Van Kirk, W. J. Murdoch, M. Radosz, Acid-active cell-penetrating peptides for in vivo tumor-targeted drug delivery, J. Am. Chem. Soc., 2013, 135, 933.

[19] (a) C. Y. Li, M. X. Yu, Y. Sun, Y. Q. Wu, C. H. Huang, F. Y. Li, A nonemissive iridium(III) complex that specifically lights-up the nuclei of living cells, J. Am. Chem. Soc., 2011, 133, 11231. (b) D. L. Ma, W. L. Wong, W. H. Chung, F. Y. Chan, P. K. So, T. S. Lai, Z. Y. Zhou, Y. C. Leung, K. Y. Wong, A highly selective luminescent switch-on probe for histidine/histidine-rich proteins and its application in protein staining, Angew. Chem. Int. Edit., 2008, 47, 3735.

[20] (a) C. Y. Li, Y. Liu, Y. Q. Wu, Y. Sun, F. Y. Li, The cellular uptake and localization of non-emissive iridium(III) complexes as cellular reaction-based luminescence probes, Biomaterials, 2013, 34, 1223. (b) C. Dolan, R. D. Moriarty, E. Lestini, M. Devocelle, R. J. Forster, T. E. Keyes, Cell uptake and cytotoxicity of a novel cyclometalated iridium(III) complex and its octaarginine peptide conjugate, J. Inorg. Biochem., 2013, 119, 65. (c) Y. B. Fan, C. Y. Li, H. Cao, F. Y. Li, D. Y. Chen, The intranuclear release of a potential anticancer drug from small nanoparticles that are derived from intracellular dissociation of large nanoparticles, Biomaterials, 2012, 33, 4220.

[21] C. P. Leamon, J. A. Reddy, Folate-targeted chemotherapy, Adv. Drug Deliver. Rev., 2004, 56, 1127.

[22] D. T. Klink, S. Chao, M. C. Glick, T. F. Scanlin, Nuclear translocation of lactosylated poly-L-lysine/cDNA complex in cystic fibrosis airway epithelial cells, Mol. Ther., 2001, 3, 831 .

[23] J. G. Ray, S. S. Naik, E. A. Hoff, A. J. Johnson, J. T. Ly, C. P. Easterling, D. L. Patton, D. A. Savin, Stimuli-responsive peptide-based ABA-triblock copolymers: unique morphology transitions with pH, Macromol. Rapid Commun., 2012, 33, 819.

[24] (a) K. Y. Zhang, H. W. Liu, T. T. H. Fong, X. G. Chen, K. K. W. Lo, Luminescent dendritic cyclometalated iridium(III) polypyridine complexes: synthesis, emission 
behavior, and biological properties, Inorg. Chem., 2010, 49, 5432. (b) K. Y. Zhang, K. K. W. Lo, Synthesis, properties, and live-cell imaging studies of luminescent cyclometalated iridium(III) polypyridine complexes containing two or three biotin pendants, Inorg. Chem., 2009, 48, 6011. (c) W. J. Tan, Q. Zhang, J. J. Zhang, H. Tian, Near-infrared photochromic diarylethene iridium (III) complex, Org. Lett., 2009, 11, 161. (d) C. H. Leung, H. J. Zhong, H. Yang, Z. Cheng, D. S. H. Chan, V. P. Y. Ma, R. Abagyan, C. Y. Wong, D. L. Ma, A metal-based inhibitor of tumor necrosis factor- $\alpha$, Angew. Chem. Int. Edit., 2012, 51, 9010. (e) D. L. Ma, V. P. Y. Ma, D. S. H. Chan, K. H. Leung, H. Z. He, C. H. Leung, Recent advances in luminescent heavy metal complexes for sensing, Coord. Chem. Rev., 2012, 256, 3087. (f) F. Galsbol, B. S. Rasmussen, The preparation, resolution, and characterization of tris(1,2-ethanediamine)iridium(III) complexes, Acta Chem. Scand A, 1982, 36, 83. (g) D. B. Grotjahn, T. L. Groy, Formation of coordinatively unsaturated Cp*Ir-amino acid complexes and their highly diastereoselective complexation reactions, $J$. Am. Chem. Soc., 1994, 116, 6969. (h) Q. Zhao, M. X. Yu, L. X. Shi, S. J. Liu, C. Y. Li, M. Shi, Z. G. Zhou, C. H. Huang, F. Y. Li, Cationic iridium(III) complexes with tunable emission color as phosphorescent dyes for live cell imaging, Organometallics, 2010, 29, 1085.

[25] (a) Y. Xin, J. Y. Yuan, Schiff's base as a stimuli-responsive linker in polymer chemistry, Polym. Chem., 2012, 3, 3045. (b) C. Wang, G. T. Wang, Z. Q. Wang, X. Zhang, A pH-responsive superamphiphile based on dynamic covalent bonds, Chem. Eur. J., 2011, 17, 3322. (c) L. Zhu, L. Zhao, X. Qu, Z. Yang, pH-sensitive polymeric vesicles from coassembly of amphiphilic cholate grafted poly(L-lysine) and acid-cleavable polymer-drug conjugate, Langmuir, 2012, 28, 11988.

[26] M. F. Hagan, O. M. Elrad, R. L. J. Jack, Mechanisms of kinetic trapping in self-assembly and phase transformation, Chem. Phys., 2011, 135, 104115.

[27] Y. P. Myer, The $\mathrm{pH}$-induced helix-coil transition of poly-L-lysine and poly-L-glutamic acid and the 238-m $\mu$ dichroic band, Macromolecules, 1969, 2, 624.

[28] L. F. Zhang, A. Eisenberg, Multiple morphologies and characteristics of "crew-cut" micelle-like aggregates of polystyrene-b-poly(acrylic acid) diblock copolymers in aqueous solutions, J. Am. Chem. Soc., 1996, 118, 3168.

[29] L. F. Zhang, A. Eisenberg, Multiple morphologies of "crew-cut" aggregates of polystyrene-b-poly(acrylic acid) block copolymers, Science, 1995, 268, 1728.

[30] M. A. Jordan, K. Wendell, S. Gardiner, W. B. Derry, H. Copp, L. Wilson, Mitotic block induced in HeLa cells by low concentrations of paclitaxel (Taxol) results in abnormal mitotic exit and apoptotic cell death, Cancer Res., 1996, 56, 816.

[31] I. D. Vladescu, M. J. McCauley, M. E. Nunez, I. Rouzina, M. C. Williams, Quantifying force-dependent and zero-force DNA intercalation by single-molecule stretching, Nat. Methods, 2007, 4, 517. 
[32] J. S. Choi, D. K. Joo, C. H. Kim, K. Kim, J. S. Park, Synthesis of a barbell-like triblock copolymer, poly(L-lysine) dendrimer-block-Poly(ethylene glycol)-block-poly(l-lysine) dendrimer, and its self-assembly with plasmid DNA, J. Am. Chem. Soc., 2000, 122, 474.

[33] G. M. Cohen, Caspases: the executioners of apoptosis, Biochem. J., 1997, 326, 1.

[34] C. C. Chen, S. W. Liou, C. C. Chen, W. C. Chen, F. R. Hu, I. J. Wang, S. J. Lin, Coenzyme Q10 reduces ethanol-induced apoptosis in corneal fibroblasts, Plos One, 2011, 6, e19111.

[35] M. Kazuo, Intracellular targeting delivery of liposomal drugs to solid tumors based on EPR effects, Adv. Drug Delivery Rev., 2011, 63, 161.

[36] S. Naito, A. C. von Eschenbach, R. Giavazzi, I. J. Fidler, Growth and metastasis of tumor cells isolated from a human renal cell carcinoma implanted into different organs of nude mice, Cancer Res., 1986, 46, 4109.

[37] L. Rao, D. Perez, E. J. White, Lamin proteolysis facilitates nuclear events during apoptosis, Cell Biol., 1996, 135, 1441. 